\title{
REVIEW \\ Associations between psychological factors and quality of life ratings in persons with spinal cord injury: a systematic review
}

\author{
CMC van Leeuwen ${ }^{1,2}$, S Kraaijeveld ${ }^{1}$, E Lindeman $^{1}$ and MWM Post ${ }^{1,2}$
}

Study design: Systematic review.

Objectives: To review the literature on relationships between psychological factors and quality of life (QOL) of persons with spinal cord injury (SCI).

Setting: NA.

Methods: A systematic literature search was conducted in several online databases (PubMed, Embase and Psychlnfo). Articles were included if they provided quantitative information on associations between QOL-related dependent variables and psychological factors as independent variables in an $\mathrm{SCl}$ population. The search was limited to empirical studies published in English. The methodological quality of the included articles was assessed.

Results: A total of 48 studies were included. Total locus of control, sense of coherence, self-worth, hope, purpose in life and positive affect were consistently associated with greater QOL. Negative affect and posttraumatic cognitions were consistently associated with lower QOL. Inconsistent evidence was found for subscales of locus of control, the role of attribution of blame, spirituality, personality, appraisals, passive coping and emotion-focused coping. No evidence was found for an association between active problem-focused coping styles and QOL.

Conclusion: Many psychological factors were strongly and consistently related to QOL, but for some others no or inconsistent evidence was found. Further research should (1) use larger study groups, preferably in longitudinal designs, (2) improve terminological precision and avoid conceptual overlap between determinants and outcomes, (3) increase uniformity of questionnaires and (4) reexamine concepts that have been abandoned prematurely, such as personality and social comparison.

Spinal Cord (2012) 50, 174-187; doi:10.1038/sc.2011.120; published online 1 November 2011

Keywords: spinal cord injury; quality of life; psychological factors; coping

\section{INTRODUCTION}

Spinal cord injury (SCI) is among the most debilitating injuries with which a person may be confronted. ${ }^{1}$ One of the principal aims of physical medicine and rehabilitation is to maximize the quality of life (QOL) of persons with SCI. ${ }^{2}$ QOL as a concept has received considerable attention in health care settings and clinical research, and has been widely used as a clinical outcome of persons with disabilities in general, and persons with SCI specifically. ${ }^{2-4}$ Although there is considerable debate about the nature, definition and operationalization of QOL, a distinction is often made between objective QOL and subjective QOL. ${ }^{3}$ The latter conceptualization may be further subdivided into a cognitive component that comprises life satisfaction, and an emotional component that includes affective states and mental health. ${ }^{3}$

Not only QOL itself, but also determinants of QOL in persons with SCI have been widely assessed. ${ }^{5}$ To date, three narrative reviews have surveyed psychological determinants of QOL in persons with SCI. ${ }^{6-8}$ The first review in 1999 covered a wide array of social and psychological factors in persons with SCI, yet did not extensively address the relationships between psychological factors and QOL. ${ }^{6}$ The second review in 2001 focused on appraisals and coping, but concluded that it remains to be determined 'to what extent other variables add to the prediction of emotional adjustment to SCI' (Galwin and Godfrey, ${ }^{7}$ p 624). A recent review in 2009 expanded upon the role of coping and appraisals in adjustment to SCI, and provided evidence for the importance of self-efficacy, social cognition, sense of coherence, purpose ${ }^{8}$ in life and locus of control (LOC) in the QOL of persons with SCI. Each of these factors was only briefly discussed, however, and the findings of different studies were not compared.

None of these reviews were systematic. Consequently, relevant studies may have been missed, and too much focus may have been placed on a relatively small group of variables. The present study, therefore, aims to supplement the literature by systematically collecting and evaluating the available evidence on the relationships between psychological factors and QOL in persons with SCI. It is hypothesized that the psychological factors found to be related to QOL in previous reviews, included coping, appraisals, self-efficacy, social cognition, sense of coherence, purpose in life and LOC, will be consistently related to QOL in persons with SCI. It is also hypothesized that other psychological factors not previously identified will be consistently related to QOL in persons with SCI.

${ }^{1}$ Rudolf Magnus Institute of Neuroscience and Center of Excellence for Rehabilitation Medicine, University Medical Center Utrecht and Rehabilitiation Center De Hoogstraat, Utrecht, The Netherlands and ${ }^{2}$ Swiss Paraplegic Research, Nottwil, Switzerland

Correspondence: Dr MWM Post, Rehabilitation Center De Hoogstraat, Rembrandtkade 10, Utrecht TM 3583, The Netherlands.

E mail: m.post@dehoogstraat.nl

Received 28 April 2011; revised 25 July 2011; accepted 12 September 2011; published online 1 November 2011 


\section{MATERIALS AND METHODS}

\section{Eligibility criteria and operationalization of concepts}

The current review is restricted to empirical studies that provide quantitative data, thus excluding qualitative studies, reviews and case reports. Only studies of SCI populations were included in which standardized measures were used to assess relationships between psychological factors (determinant) and QOL (outcome). The review was further limited to studies in the English language that were published in peer-reviewed journals. To maximize the scope of the review, no constraint was placed on the year of publication of potentially relevant studies; the search date (29 November, 2010) formed the only temporal cutoff point

\section{QOL}

QOL was operationalized as subjective QOL, which was split into two elements: a cognitive component that comprises life satisfaction and an emotional component that encompasses mental health. Mental health, in this manuscript, is used as a general term that covers psychological and affective reactions to what is happening in a person's life, in particular depression, anxiety, posttraumatic stress and emotional distress.

\section{Psychological factors}

The search included the terminology pertaining to psychological factors, as described in previous reviews. ${ }^{6-8}$ Additional search terms, such as 'psychological factor', 'psychological variable' and 'personal characteristic', were incorporated to broaden the search and to find psychological factors not described in previous reviews.

Coping strategies were sorted into the following three broad categories: active problem-focused coping, passive coping and emotion-focused coping. ${ }^{9}$ These categories do not necessarily adhere to the classifications of the original researchers, although these were followed as closely as possible; the classification is solely to facilitate comparisons between studies.

\section{Search strategy}

A computerized search of the online databases Embase, PsychInfo and Pubmed was executed and completed on 29 November 2010. The search was conducted in triadic terms, combining an 'SCI' domain with a 'psychological factor' determinant and a 'QOL' outcome. Supplementary Appendix 1 provides an expansion of all search terms entered in PsychInfo. The list of search terms was compiled together with an information specialist. The reference lists of selected articles and SCOPUS, a large abstract and citation database of peer-reviewed literature, were furthermore examined in order to supplement the database search.

To minimize selection bias, the initial database search was conducted independently by two researchers ( $\mathrm{CvL}$ and $\mathrm{SK}$ ), as was the subsequent screening and selection of articles. Concurrence between both researchers with regard to the selection of articles was calculated using the $\kappa$ statistic for chancecorrected agreement. At each step of the process, disagreement regarding selection was discussed and settled with reference to the explicit inclusion criteria. If, after discussion, no agreement could be reached, another author (MP) was consulted for a final judgment.

\section{Quality assessment}

The assessment of the methodological quality of individual studies was conducted independently by two researchers ( $\mathrm{CvL}$ and $\mathrm{SK}$ ) according to an 8-point checklist, resulting in a score that ranged from lowest quality (1) to the highest quality (8) (Supplementary Appendix 2). The checklist is a combination of the methodological quality list developed by Kwakkel et al., ${ }^{10}$ and the checklist to evaluate the quality of studies designed by Downs and Black. ${ }^{11}$ These two instruments were merged to obtain a brief, clear and easy to use checklist. The level of agreement between the researchers' ratings was established using the intraclass correlation coefficient (ICC).

\section{Data extraction}

The most frequently reported statistics in the selected articles were correlation coefficients, which were considered weak below 0.3 , moderate between 0.3 and 0.5 and strong above $0.5{ }^{12}$ Aside from correlations, standardized $\beta$-coefficients, changes in $R^{2}$ and differences between means were extracted where available.
Psychological factors were classified as consistent determinants if all bivariate associations reported were statistically significant, and if the majority of these associations were moderate $(0.3-0.5)$ or strong $(>0.5)$. Variables were classified as inconsistent determinants if only some of the associations were statistically significant, or if most significant associations were weak. Variables were classified as unrelated to mental health and life satisfaction if all or nearly all associations were nonsignificant.

\section{RESULTS}

\section{Search strategy and quality assessment}

The search strategy produced a total of 730 articles (Figure 1). After removing 321 duplicates, a further 331 articles were removed after screening titles and abstracts. Screening full texts led to the removal of 33 more articles. Agreement between both raters was high for the selection of titles and abstracts (Cohen's $\kappa=0.96$ ). The screening of reference lists produced three additional articles. This left a total of 48 studies for inclusion in the final review. The characteristics of these studies are presented in Table 1. The different instruments that were used to measure QOL and the psychological factors are presented in Tables 2 and 3.

Agreement between the two raters on methodological quality assessment was acceptable (ICC $=0.78$ ). The assessment revealed that on an 8-point scale, the average score was 5.1 (range 2-8), and most studies attained a score between 4 and 6 (see Appendix 3). Although more recent studies (2001-2010) were slightly higher rated (mean of 5.2) than older studies (1985-2000: mean of 4.9), there was

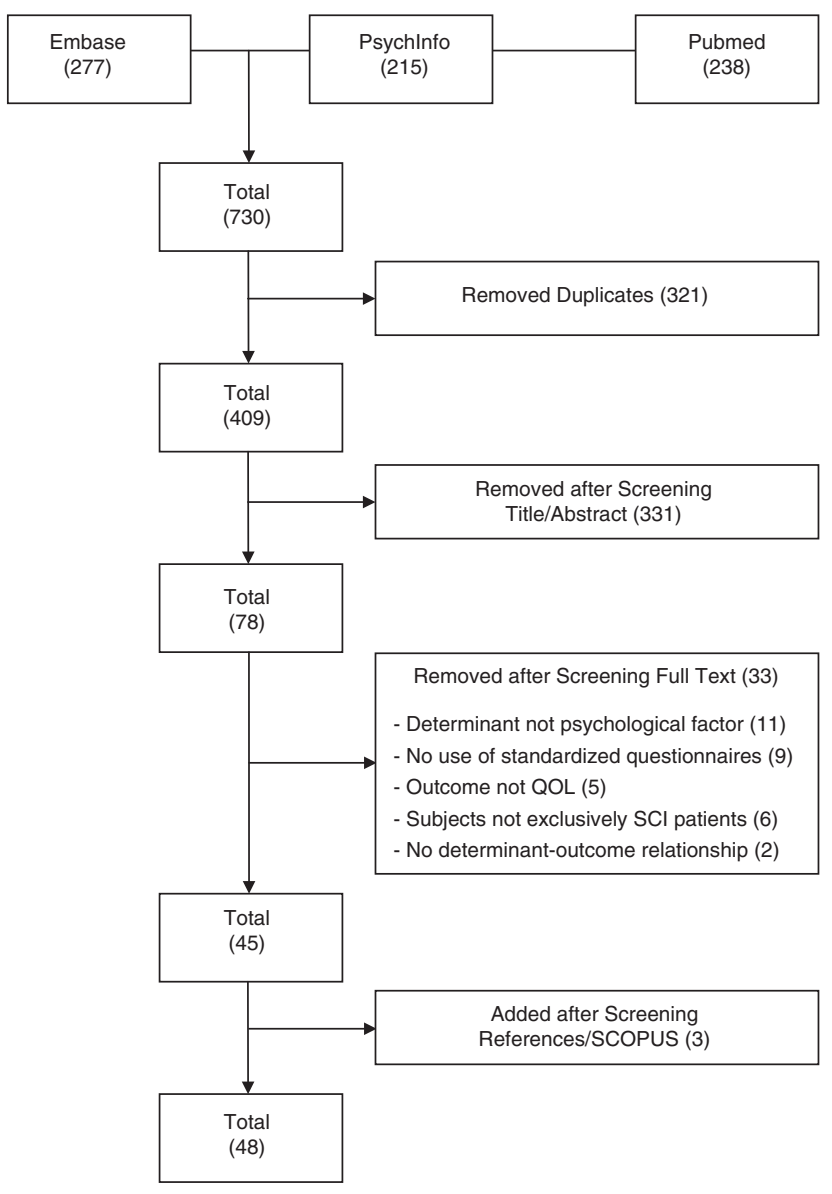

Figure 1 Search flowchart. 
only one study that achieved a score of 8 and only four studies with a score of 7. Therefore, though the methodological quality of studies may be increasing over time, this is still an area that is fit for improvement.
Psychological factors

In this section, an overview is presented of the relationships between psychological factors and QOL. The actual figures are displayed in Table 4.

Table 1 Patient characteristics

\begin{tabular}{|c|c|c|c|c|c|c|c|c|c|}
\hline \multicolumn{4}{|c|}{ Number of SCI subjects } & \multirow[t]{2}{*}{$A g e^{a}$} & \multirow[t]{2}{*}{ Time since injury ${ }^{a}$} & \multicolumn{4}{|c|}{ Type of SCI } \\
\hline Reference & Total & Male & Female & & & Tetraplegia & Paraplegia & Complete & Incomplete \\
\hline 13 & 100 & 75 & 25 & 40 & $1-5(r)$ & 58 & 42 & 39 & 61 \\
\hline 14 & 158 & 120 & 38 & 36 & 12 & $\sim 115$ & $\sim 43$ & - & - \\
\hline 15 & 100 & 90 & 10 & 56 & 20 & 33 & 67 & 31 & 69 \\
\hline 16 & 127 & $\sim 66$ & $\sim 61$ & 39.3 & $>2$ & $\sim 66$ & $\sim 61$ & $\sim 66$ & $\sim 61$ \\
\hline 17 & 1391 & $\sim 1112.8$ & $\sim 278.2$ & 40.1 & 8.9 & $\sim 765$ & $\sim 653$ & - & - \\
\hline 18 & 47 & 44 & 9 & 30.5 & 3.63 & 33 & 20 & - & - \\
\hline 19 & 53 & 44 & 9 & 30.5 & 3.63 & 33 & 20 & - & - \\
\hline 20 & 62 & 43 & 19 & 45.1 & 1.73 & $\sim 36$ & $\sim 26$ & - & - \\
\hline 21 & 57 & 47 & 10 & 30.3 & 1.86 & 35 & 22 & $\sim 18$ & $\sim 39$ \\
\hline 22 & 43 & 31 & 12 & 35.6 & 3.7 & - & - & 20 & 23 \\
\hline 23 & 30 & 25 & 5 & 45.4 & 11.6 & - & - & 10 & 20 \\
\hline 24 & 50 & 43 & 7 & 38.9 & $0.25-2(r)$ & 30 & 20 & 34 & 16 \\
\hline 25 & 102 & 83 & 19 & 45.7 & 15.3 & 46 & 56 & 55 & 47 \\
\hline 26 & 18 & 18 & 0 & 25.9 & - & 18 & 0 & 14 & 4 \\
\hline 27 & 58 & 45 & 13 & 35.8 & - & $\sim 26$ & $\sim 32$ & - & - \\
\hline 28 & 26 & $\sim 22.9$ & $\sim 3.1$ & 39 & 8.4 & $\sim 14$ & $\sim 12$ & - & - \\
\hline 29 & 28 & 24 & 4 & 32 & 7.1 & 16 & 12 & - & - \\
\hline 30 & 78 & 59 & 19 & 31.7 (a.i.) & 3.61 & \multicolumn{4}{|c|}{ Tetraplegia (31), paraplegia (29), frankel D (18) } \\
\hline 31 & 70 & $\sim 44.1$ & $\sim 25.9$ & 43.9 & $15 \leqslant 6 ; 55 \geqslant 7$ & Tetraplegia $(\sim 12)$, p & ther lesions $(\sim 10)$ & - & - \\
\hline 32 & 20 & 15 & 5 & 31.1 & 2.9 & 20 & 0 & - & - \\
\hline 33 & 237 & 187 & 50 & 38.2 & $6 \mathrm{wks} / 12 \mathrm{wks} / 1 \mathrm{yr}$ & 109 & 126 & 115 & 120 \\
\hline 34 & 266 & 208 & 58 & 37.5 & 6 wks/12wks & \multicolumn{2}{|c|}{ Tetraplegia (104), paraplegia (125), unknown (25) } & 113 & 118 \\
\hline 38 & 93 & $\sim 82.8$ & $\sim 10.2$ & 39.5 & $0.25-1.25$ (p.d.) & - & - & - & - \\
\hline 35 & 87 & 59 & 28 & 47.3 & 26.9 days & 38 & 49 & 27 & 60 \\
\hline 36 & 242 & $\sim 160$ & $\sim 82$ & 44.6 & 10.6 & \multicolumn{2}{|c|}{ Cervical (124), thoracic (98), lumbar (16), sacral (4) } & - & - \\
\hline 37 & 54 & 43 & 11 & $16-83(r)$ & 0.52 & 27 & 27 & 22 & 32 \\
\hline 39 & 79 & 76 & 3 & 55.9 & 1.5 & 38 & 41 & 24 & 55 \\
\hline 40 & 75 & 57 & 18 & 39.6 & 7.56 & 43 & 32 & - & - \\
\hline 41 & 444 & - & - & - & $10-30(r)$ & - & - & - & - \\
\hline 42 T1 & 41 & 34 & 7 & $16-65(r)$ & 29.1 (a.i.) & 22 & 19 & - & - \\
\hline 42 T2 & 30 & 18 & 12 & $16-65(r)$ & 5.5 & 13 & 17 & - & - \\
\hline 43 & 87 & $\sim 70.5$ & $\sim 16.5$ & 31.4 (a.i.) & NA & $\sim 28$ & $\sim 59$ & - & - \\
\hline 44 & 37 & 30 & 7 & 40.9 & 9.9 & 15 & 22 & 27 & 10 \\
\hline 45 & 38 & 25 & 13 & 32.5 & - & - & - & - & - \\
\hline 46 & 91 & 73 & 18 & $18-50(r)$ & 9.5 & - & - & - & - \\
\hline 47 & 119 & $\sim 72.6$ & $\sim 46.4$ & 26 & $2-5(r)$ & \multicolumn{2}{|c|}{ Cervical (17), thoracic (38), lumbar (45) } & 53 & 47 \\
\hline 48 & 127 & 88 & 39 & 43 & $>2$ & \multicolumn{2}{|c|}{ Cervical (72), thoracic (43), lumbar (12) } & $\sim 74$ & $\sim 53$ \\
\hline 49 & 100 & 78 & 22 & 34.4 & $>2$ & \multicolumn{2}{|c|}{ Cervical (24), thoracic (49), lumbar (27) } & 60 & 40 \\
\hline 50 & 106 & 80 & 26 & 46.7 & 8.6 & $\sim 39$ & $\sim 67$ & $\sim 41$ & $\sim 65$ \\
\hline 51 & 90 & 87 & 3 & 32.6 & 8.32 & 37 & 53 & - & - \\
\hline 52 & 80 & 51 & 29 & 39.8 & 8.1 & $\sim 49$ & $\sim 31$ & - & - \\
\hline 53 & 105 & - & - & 41.1 & 17.9 & $\sim 77$ & $\sim 28$ & $\sim 59$ & $\sim 46$ \\
\hline 54 & 286 & 232 & 54 & 41.9 & 18.6 & 174 & 112 & - & - \\
\hline 55 & 313 & $\sim 267.1$ & $\sim 45.9$ & 49.7 & 12.4 & - & - & - & - \\
\hline 56 & 81 & 54 & 27 & 50.4 & $0.25-1.5(r)$ & \multicolumn{2}{|c|}{ Tetraplegia (40), paraplegia (23), unknown (9) } & - & - \\
\hline 57 & 279 & 176 & 101 & 51.1 & 11.8 & 113 & 152 & 115 & 157 \\
\hline 58 & 256 & 191 & 65 & 43.9 & 8.9 & \multicolumn{2}{|c|}{ Tetraplegia (81), paraplegia (86), all levels (85) } & - & \\
\hline 59 & 443 & 345 & 98 & 51.8 & 19.2 & 157 & 285 & 181 & 261 \\
\hline 60 & 35 & 28 & 7 & 32 & - & - & - & - & - \\
\hline
\end{tabular}

Abbreviations: a.i., (age) at injury; p.d., post discharge; $r$, range; $\mathrm{SCl}$, spinal cord injury; wks, weeks; yr, year.

$\sim$, numbers rounded/calculated by authors. 
Table 2 Quality of life questionnaires

\begin{tabular}{|c|c|}
\hline QOL outcome & Questionnaire \\
\hline Life satisfaction & $\begin{array}{l}\text { LSIA-A: Life Satisfaction Index; }{ }^{14,15,45} \text { LSI-Z: Life Satisfaction Index-Z; }{ }^{30} \text { LSS: Life Situation Survey; }{ }^{47,49} \text { EORTC QLQ-C30: European } \\
\text { Organisation for Research and Treatment of Cancer Quality of Life Questionnaire Core } 30 ;{ }^{58} \text { SWLS: Satisfaction With Life Scale; }{ }^{35,36,40} \text { QOLS: } \\
\text { Quality of Life Scale; }{ }^{55} \text { QLI: Quality of Life Index; }{ }^{38} \text { Quality of Life: in } 15 \text { key areas; }{ }^{13} \text { COMQL-A5: Comprehensive Quality of Life Scale for } \\
\text { Adults, 5th edition; }{ }^{49} \text { LSQ: Life Satisfaction Questionnaire; }{ }^{54,56} \text { MAP: Multi-dimensional Adjustment Profile; }{ }^{16,53} \text { (Revised version of the LSQ); } \\
\text { COMQoL-A5: Comprehensive Quality of Life scale for adults, } 5 \text { th edition-one question; }{ }^{59} \text { two questions concerning general health and general } \\
\text { well-being; }{ }^{57} \text { one question with a VAS scale from } 1 \text { to } 7 ;{ }^{46} \text { ladder of adjustment; }{ }^{17}\end{array}$ \\
\hline Psychological well-being & $\begin{array}{l}\text { IPWB: Index of Psychological Well-Being; }{ }^{15,48,49} \text { SF-36: Medical Outcomes Study } 36-\text { Item Short Form Health Survey-mental health } \\
\text { subscale; }{ }^{28,50,58} \text { SWBI: Sense of Well-Being Inventory; }{ }^{36,39} \text { WHOQOL-BREF: World Health Organization Quality of Life Scale: psychological } \\
\text { domain ;32-34 }\end{array}$ \\
\hline Depression & $\begin{array}{l}\text { CES-D: Center for Epidemiologic Studies-Depression Scale; }{ }^{15,52} \text { BDI: Beck Depression Inventory; }{ }^{18,19,22,26,27,42-44,60} \text { IDD: Inventory to } \\
\text { Diagnose Depression; }{ }^{51} \text { HADS: Hospital Anxiety and Depression Scale; }{ }^{32-34,37} \text { (also measures anxiety) ; DASS-21: Depression Anxiety and } \\
\text { Stress Scale; }{ }^{59} \text { (also measures anxiety) ; PHQ-9: Patient Health Questionnaire; }{ }^{55} \text { AIMS: Arthritis Impact Measurement Scales; }{ }^{31} \text { SCI QL-23: } \\
\text { Spinal Cord Injury Quality of Life Questionnaire; }{ }^{58}\end{array}$ \\
\hline Anxiety & STAI: Spielberger Trait Anxiety Inventory; ${ }^{22}$ SAI: State Anxiety Inventory; ${ }^{42-44}$ DAS: Death Anxiety Scale; ${ }^{55}$ \\
\hline $\begin{array}{l}\text { Posttraumatic stress } \\
\text { and emotional distress }\end{array}$ & $\begin{array}{l}\text { PPTSD: Purdue Posttraumatic Stress Disorder-Revised Scale; }{ }^{55} \text { IES-R: Impact of Events-Revised; }{ }^{24,25,59} \text { Posttraumatic Stress Disorder List; }{ }^{20} \\
\text { PDS: Posttraumatic Diagnostic Scale; }{ }^{24} \text { PAIS: Psychological Adjustment to IIIness Scale; }{ }^{42} \text { SCL-90: Symptom Checklist-90-Revised; }{ }^{19,21,23,29}\end{array}$ \\
\hline
\end{tabular}

Locus of control (LOC). Total LOC was moderately to strongly associated with higher QOL in all three studies in which it was assessed. ${ }^{13-15}$ Internal LOC was assessed in seven studies, ${ }^{16-22}$ with five of eight computed associations being significant. Weak-to-moderate positive correlations were found with higher life satisfaction, ${ }^{16,17}$ less depression, ${ }^{18,19}$ and with lower posttraumatic stress. ${ }^{20}$ External LOC was associated with greater psychological distress in one study. ${ }^{23}$ External LOC can be further divided into perceptions of other people (others' LOC) and chance events as (chance LOC). For others' LOC, only two out of six associations were significant. ${ }^{16,17,20-22}$ Others' LOC was weakly associated with lower life satisfaction ${ }^{17}$ and with more posttraumatic stress. ${ }^{20}$ For chance LOC, only half of the six associations were significant. ${ }^{16,17,20-22}$ Chance LOC correlated weakly with lower life satisfaction, ${ }^{16,17}$ and moderately with higher levels of depression. ${ }^{22}$

Attribution of blame. In all, 7 of 13 associations between blaming oneself for one's SCI and QOL were significant. ${ }^{15,23-30}$ Self-blame was associated weakly with higher life satisfaction, ${ }^{15}$ lower posttraumatic stress $^{25}$ and lower psychological distress. ${ }^{23}$ Inconsistently, self-blame was also correlated with greater depression in one study, ${ }^{26}$ and with less depression in two other studies. ${ }^{15,27}$ High self-blamers were more anxious than low self-blamers. ${ }^{27}$ Blaming others was only associated with QOL in one ${ }^{31}$ of three studies, ${ }^{26,28,31}$ in which it was strongly associated with depression. No association was found between blaming the SCI on chance or on the environment and QOL. ${ }^{26,28}$ Perceived avoidability of the SCI was weakly associated with higher life satisfaction, greater psychological well-being and less depression. ${ }^{15}$

Sense of coherence. All 11 associations between SOC and QOL were significant. ${ }^{32-34}$ SOC was strongly associated with greater psychological well-being, ${ }^{32-34}$ and moderately with lower levels of depression and anxiety. ${ }^{33,34}$

Positive factors. Seven out of eight associations between hope and QOL were significant. ${ }^{35-37}$ Hope was associated with higher life satisfaction, ${ }^{35,36}$ greater psychological well-being ${ }^{36}$ and with lower levels of depression and anxiety. ${ }^{37}$ Purpose in life was addressed in three studies, in which strong associations between greater purpose in life and higher life satisfaction, ${ }^{17,38}$ and higher psychological wellbeing ${ }^{39}$ were found.
Spirituality. In total, 6 out of 16 associations between spirituality and QOL were significant. ${ }^{40-44}$ Total scores on a measure of spirituality were associated with higher life satisfaction. ${ }^{40,41}$ Spirituality has been split in the literature along the dimensions of religious and existential spirituality. Religious spirituality was weakly associated. In contrast, existential spirituality was strongly associated with higher life satisfaction, however, it was only measured in one study. ${ }^{40}$

Self-worth. In all, 20 out of 24 associations between perceptions of self-worth and QOL were significant. ${ }^{35,36,38,45-52}$ Self-esteem was associated with higher life satisfaction, ${ }^{36,45,46}$ greater psychological well-being ${ }^{36}$ and lower depression. ${ }^{46}$ Self-efficacy has been studied more intensively, and associations have been found with higher life satisfaction, ${ }^{35,38,47,49}$ and with greater psychological well-being. ${ }^{48-50}$ Self-efficacy was associated with less depression in two studies. ${ }^{51,52}$

Personality. Only 6 out of 15 correlations between personality factors and QOL were significant. ${ }^{17,53}$ One study examined the Big Five traits, and found a significant positive correlation between life satisfaction and extraversion. ${ }^{53}$ Neuroticism was strongly positively correlated with emotional distress, ${ }^{53}$ whereas neuroticism/anxiety was moderately negatively correlated with life satisfaction. ${ }^{17}$ Sociability was weakly positively correlated with life satisfaction, whereas the correlation with aggression/hostility was weakly negative. ${ }^{17}$

Affect. In total, 14 out of 17 associations between affect and QOL were significant. ${ }^{25,35,38,54,55}$ Positive affect was associated with higher life satisfaction ${ }^{35,54}$ whereas negative affect was associated with lower life satisfaction ${ }^{35,38}$ and higher posttraumatic stress. ${ }^{25}$

Appraisals. In total, 30 out of 53 associations between appraisals and QOL were significant. ${ }^{33,34,37,56,57}$ Overwhelming disbelief, fearful despondency and negative perceptions of one's disability were associated with lower life satisfaction, ${ }^{56}$ whereas growth and resilience were associated with greater life satisfaction. ${ }^{56,57}$ The appraisals threat, challenge and loss have been employed in two studies. ${ }^{33,34}$ Moreover, one study examined the appraisals threat, challenge and control. ${ }^{37}$ Threat appraisals were associated with lower life satisfaction, ${ }^{34}$ lower psychological well-being, ${ }^{33}$ and with greater depression and anxiety. ${ }^{33,34,37}$ Challenge appraisals were associated with higher life satisfaction, ${ }^{34}$ and lower depression and 
Table 3 Psychological Factors: operationalization and questionnaires

\begin{tabular}{|c|c|}
\hline Psychological factor & Operationalization of psychological factor \\
\hline \multicolumn{2}{|l|}{ 1. Locus of control } \\
\hline $\begin{array}{l}\text { Total perceived } \\
\text { control }\end{array}$ & $\begin{array}{l}\text { The belief that a person can direct one's life, has the power to make } \\
\text { decisions based upon individual preferences, and can change the course } \\
\text { of a persons' life (Nosek, Fuhrer \& Howland, 1992) }\end{array}$ \\
\hline $\begin{array}{l}\text { Internal locus of } \\
\text { control }\end{array}$ & $\begin{array}{l}\text { Health-related beliefs that reflect varying levels of dimensions of locus of } \\
\text { control (Levenson, 1974) }{ }^{18}\end{array}$ \\
\hline $\begin{array}{l}\text { External locus of } \\
\text { control: others } \\
\text { and chance }\end{array}$ & \\
\hline $\begin{array}{l}\text { 2. Attribution of } \\
\text { blame }\end{array}$ & $\begin{array}{l}\text { The assessment of an individual's attribution of accountability for his/her } \\
\mathrm{SCl}^{28}\end{array}$ \\
\hline
\end{tabular}

Self-blame

Others blame

Chance

Environment

3. Sense of coherence

4. Positive factors Hope Purpose in life

\section{Spirituality}

Religious

Existential

6. Self-worth

Self-esteem

Self-efficacy

7. Personality

8. Affect

Positive

Negative

9. Appraisals
To what extent the subject believes that the $\mathrm{SCl}$ was caused by themselves 28

To what extent the subject believes that other people caused the injury ${ }^{28}$

To what extent the subject believes that luck or fate caused their injury ${ }^{28}$

To what extent the subject believes that external factors such as the

weather caused their $\mathrm{SCl}^{28}$

The degree to which a person experiences that his/her life situation is comprehensible, manageable and meaningful ${ }^{34}$

A person's current evaluation of their goal-directed thinking 37

The degree to which an individual perceives himself or herself to find meaning in his/her life ${ }^{17}$

A person's overall level of spirituality 40

The participant's view of their relationship with God, and the sense of satisfaction and positive connection with God 40

A participant's level of life perspective and purpose ${ }^{40}$

Individual's global positive or negative feelings towards himself or herself (Rosenberg, 1979) 36

One's belief or sense of confidence in his/her own ability ${ }^{50}$

Major domains of normal adult personality ${ }^{53}$

Positive affect reflects feelings of joy, excitement and vigour ${ }^{54}$

Negative affect indicates feelings of anger and dispair ${ }^{54}$

The way in which an individual thinks about or 'appraises' a situation ${ }^{33}$

Higher order cognitive processes and an evaluation on the availability of coping resources, their sufficiency in the current environment and the likelihood that they can be used in the current situation (Galvin and Godfrey, 2001) ${ }^{56}$
Questionnaires

Degree of control respondents felt they had in key life areas; ${ }^{13}$ perceived control subscale of the Personal Independence Profile; ${ }^{14}$ five Likert items; ${ }^{15}$

Multidimensional Health Locus of Control scale $16-21,23$

Recovery LOC Scale (RLOC) ${ }^{22}$

2 Likert items; ${ }^{15}$ seven items on a 7-point scale; ${ }^{23}$ self-blame scale of the Posttraumatic Cognitions Inventory (PCI); ${ }^{24,25}$ Bulman and Wortman's five-item questionnaire; ${ }^{26-28}$ self-blame scale of the Ways of Coping Questionnaire (WOC); ${ }^{29,30}$ self-blame scale of Coping Strategies Questionnaire $(C S Q)^{31}$

SOC-2932-34

Hope Scale; ${ }^{35}$ Adult Dispositional Hope Scale; ${ }^{36}$ the state hope Scale ${ }^{37}$ Purpose in life scale; ${ }^{17,39}$ Life Orientation Test $^{38}$

Ellison's Spiritual Well-Being Score (SWBS); ${ }^{40}$ Functional Assessment of Chronic Illness Therapies-Spiritual (FACIT-SP); ${ }^{41}$ religion domain of the COPE inventory $42-44$

The Rosenberg self-esteem scale $36,45,46$

General Self-Efficacy scale; ${ }^{38,47-49}$ Benefit finding Scale; ${ }^{35}$ Moorong Self-Efficacy Scale (MSES); ${ }^{50}$ Problem-Solving Inventory (PSI); ${ }^{51}$ The Beliefs Scale (BS) ${ }^{52}$

Zuckerman Personality Questionnaire (ZKPQ); ${ }^{17}$ NEO Personality Inventory (NEO-PI) ${ }^{53}$

Positive and Negative Affect Schedule (PANAS); ${ }^{25,35}$ Profile of Mood States (POMS); ${ }^{38}$ positive and negative domain of the Multidimensional Personality Questionnaire; ${ }^{54}$ Reactions to Impairments and Disability Inventory (RIDI) 55

Appraisal of Life Events (ALE); ${ }^{33,34}$ The Pakenham scale; ${ }^{37}$ APAPSS Scale; ${ }^{56}$ IIIness Cognition Questionnaire (ICQ $)^{57}$ 
Table 3 (Continued)

\begin{tabular}{|c|c|c|}
\hline Psychological factor & Operationalization of psychological factor & Questionnaires \\
\hline $\begin{array}{l}\text { 10. Post-traumatic } \\
\text { cognitions }\end{array}$ & Trauma-related thoughts and beliefs ${ }^{24,25}$ & Posttraumatic Cognitions Inventory $(\mathrm{PCI})^{24,25}$ \\
\hline 11-13. Coping & $\begin{array}{l}\text { The strategies brought to bear by an individual as a psychological } \\
\text { response to a stressful situation } 42\end{array}$ & $\begin{array}{l}\text { Ways of Coping Questionnaire (WOC); }{ }^{19,21,29,30} \text { Acceptance of IIIness } \\
\text { Scale; }{ }^{25} \text { Acceptance of Disability Scale (AD); }{ }^{29} \text { Coping Strategies } \\
\text { Questionnaire (CSQ); }{ }^{31} \text { Spinal Cord Lesion-related Coping Strategies } \\
\text { Questionnaire (SCL CSQ); }{ }^{33,34,36,37,58} \text { COPE; }{ }^{33,35,42-44} \text { Proactive } \\
\text { Coping Inventory; }{ }^{36} \text { Sense of Humor Questionnaire; }{ }^{36} \text { Perceived StresS } \\
\text { Scale-4; }{ }^{36} \text { Dysfunctional Attitudes Scale; }{ }^{36} \text { Helplessness subscale of } \\
\text { the Attitudes Index (AI); }{ }^{52} \text { IIIness Cognition Questionnaire (ICQ); }{ }^{57} \\
\text { Coping Strategies Scale; }{ }^{59} \text { Ways of Coping Checklist-Revised }\end{array}$ \\
\hline
\end{tabular}

anxiety. ${ }^{33,34,37}$ Loss appraisals were associated with lower life satisfaction, and higher levels of depression and anxiety. ${ }^{34}$ Control appraisals were associated with higher levels of anxiety. ${ }^{37}$

Posttraumatic cognitions. Seven of eight associations between negative posttraumatic cognitions and QOL were significant. The total score on a measure of posttraumatic cognitions, as well as posttraumatic cognitions about the self and the world, were associated with greater posttraumatic stress. ${ }^{24,25}$

Active problem-focused coping. In total, 18 of the 77 associations between active problem-focused coping variables and QOL were significant. ${ }^{21,29-31,33,34,36,37,42-44,58,59}$ All active problem-focused coping variables showed more nonsignificant than significant relationships, and did not show consistent relationships with QOL outcome measures over time.

Passive coping. In total, 45 out of 78 associations were significant. ${ }^{30,33-}$ $35,37,42-44,49,52,55,57-59$ For the coping variables that were longitudinally examined, mental disengagement, behavioral disengagement and alco$\mathrm{hol} / \mathrm{drug}$ use were related to greater depression and anxiety. ${ }^{42-44}$ Denial showed an inconsistent relationship to QOL outcomes, correlating positively with greater life satisfaction in a cross-sectional study, ${ }^{55}$ and positively with depression and anxiety in several longitudinal studies. ${ }^{42-}$ ${ }^{44}$ Escape/avoidance, helplessness and social reliance were moderately to strongly associated with QOL outcomes. ${ }^{30,33,34,52,55,57,58}$

Emotion-focused coping. Of the emotion-focused coping determinants, 43 out of 66 associations were significant. ${ }^{21,29,33,34,36,37,42-44,57,58}$ Acceptance showed the most consistent relationship with QOL, being associated with greater life satisfaction, ${ }^{36,57-59}$ psychological wellbeing, ${ }^{33,34,36,58}$ and with lower levels of depression ${ }^{33,34,37,42-44,57,58}$ and anxiety. ${ }^{34,42-44}$ Furthermore, the coping variable focus on emotions, which was longitudinally examined, was associated with greater depression and anxiety. ${ }^{42-44}$ Humor, which was also longitudinally examined, showed an inconsistent relationship with anxiety, correlating negatively and positively with anxiety over time. ${ }^{42-44}$ Wishful thinking and perceived stress were associated with lower life satisfaction and lower psychological well-being. ${ }^{36}$ Wishful thinking was also associated with greater depression. ${ }^{31}$

In all, 3 out of 21 studies on coping could not be classified in the global tripartite characterization used in this review. ${ }^{19,59,60}$ Two studies examined distinct clusters of coping styles in persons with SCI. ${ }^{19,60}$ One of these studies found that subjects in cluster 1 utilized more wishful thinking, mixed coping, growth coping and self-blame coping than subjects in cluster 2, and also reported higher depression scores and experienced more psychological distress. ${ }^{19}$ The other study found that cluster 1, the more emotion-focused group, was distinguished from cluster 2 primarily by low use of problem-focused coping and social support seeking along with higher levels of wishful thinking, and reported high depression scores. ${ }^{60}$ Finally, a high emotional distress group had a significantly higher mean on threat minimization than a low distress group. ${ }^{59}$

Miscellaneous variables. Several determinants were examined in only a single study and are not displayed in Table 4. Social comparison exhibited a relationship with QOL, as a strong correlation $\left(r=0.73^{*}\right)$ was found between greater depression and upward contrast (that is, contrasting oneself with those who are better off), as well as downward identification (that is, identifying oneself with those who are worse off, $\left.r=0.53^{*}\right) .{ }^{31}$ Death anxiety was weakly correlated with life satisfaction $\left(r=-0.124^{*}\right) .{ }^{55}$ Anger was associated with lower life satisfaction $\left(-0.41^{*}\right)$ and greater depression $(0.57 *) .57$ Cognitive distortions correlated moderately with greater levels of depression $\left(0.61^{*}\right) .52$

\section{DISCUSSION}

The purpose of the present review was to collect and assess the available evidence of the relations between psychological factors and QOL in persons with SCI. In total, we found 48 articles of which 32 articles have not been described in the three earlier reviews. The methodological quality of most of these studies was not very good.

The first hypothesis, that the psychological factors found to be related to QOL in previous reviews are consistently related to QOL in persons with SCI, was partly supported. Sense of coherence, total LOC, purpose in life and self-efficacy were indeed strongly and consistently related to QOL. However, two prevalent concepts in psychological literature, coping and appraisals, showed inconsistent results, which warrants further study. The second hypothesis, that other psychological factors not previously identified are consistently related to QOL in persons with SCI, was supported. The following psychological factors were strongly and consistently associated with QOL after SCI: selfesteem, hope, affect (positive and negative) and posttraumatic cognitions. However, the status of affect and posttraumatic cognitions as determinants rather than outcome is not self-evident; they may be a part of QOL rather than being separate determinants.

\section{Consistent determinants}

The most consistent determinants of QOL in the literature are a person's total perceived degree of control in life, their sense of 


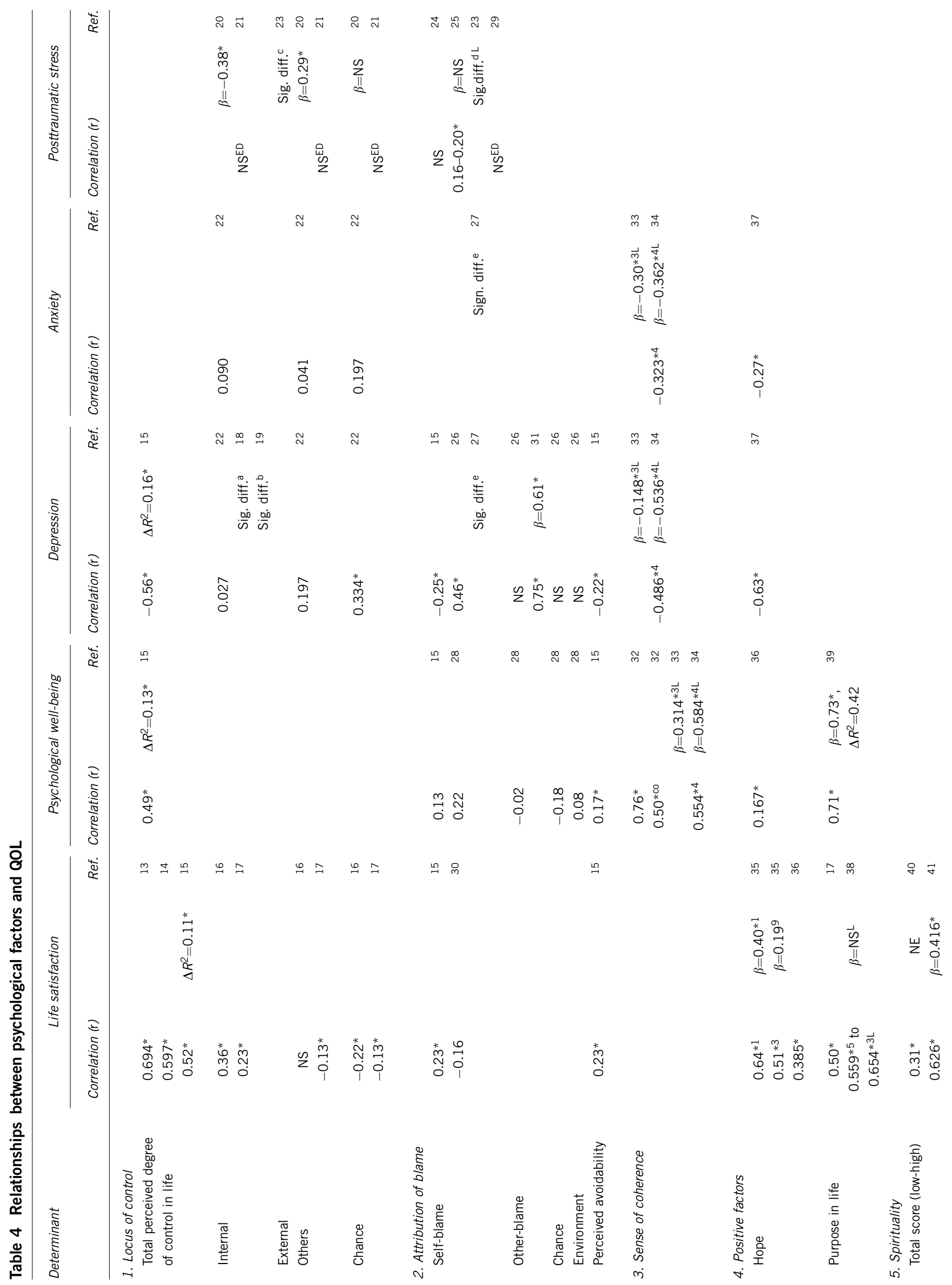




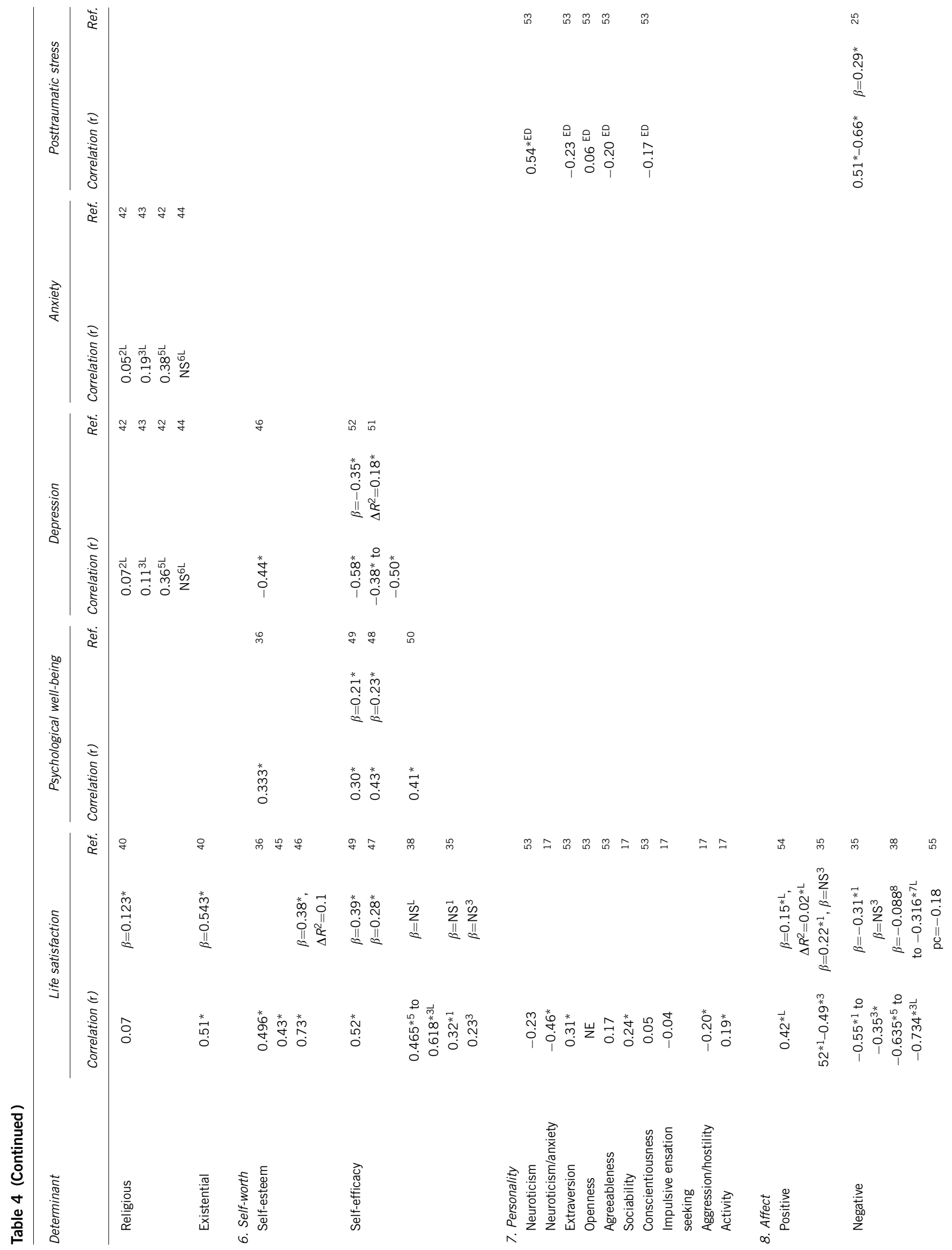


182

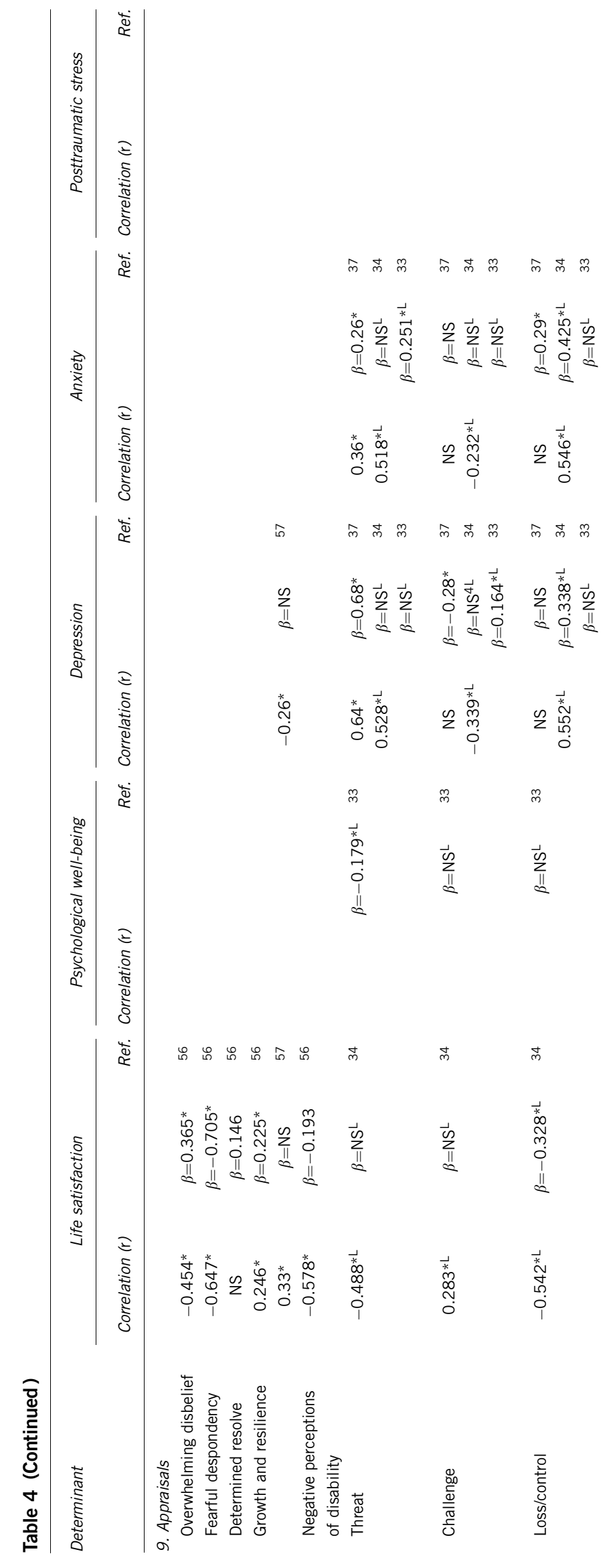

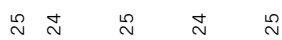

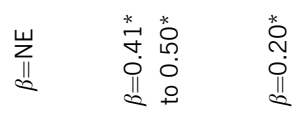

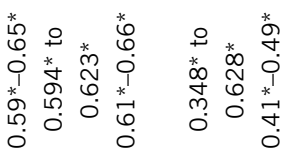

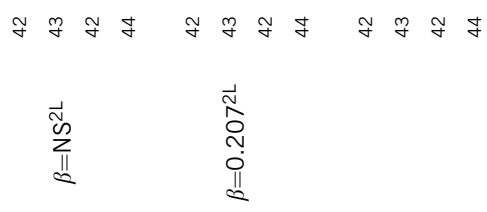

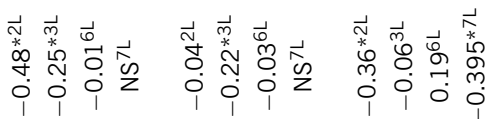
สำ<smiles>[CH]1C=C[CH-]1</smiles>

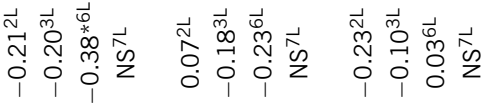
$\stackrel{\infty}{\infty}$ $\underset{\substack{* \\ \infty \\ \stackrel{0}{0}}}{\stackrel{0}{0}}$
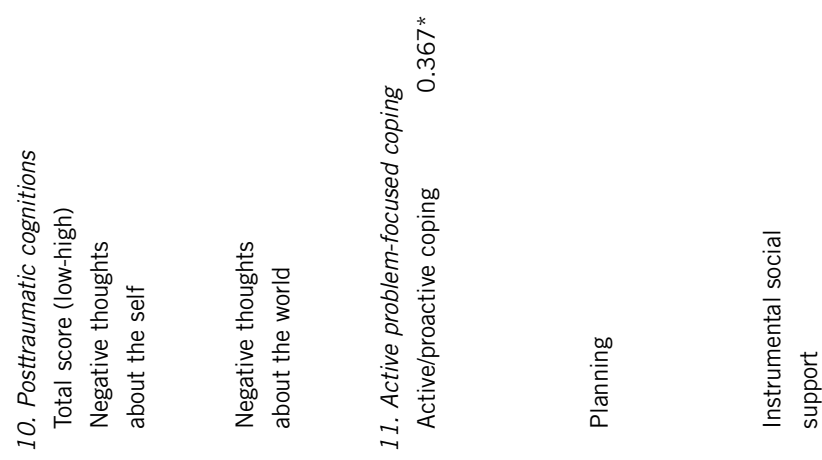


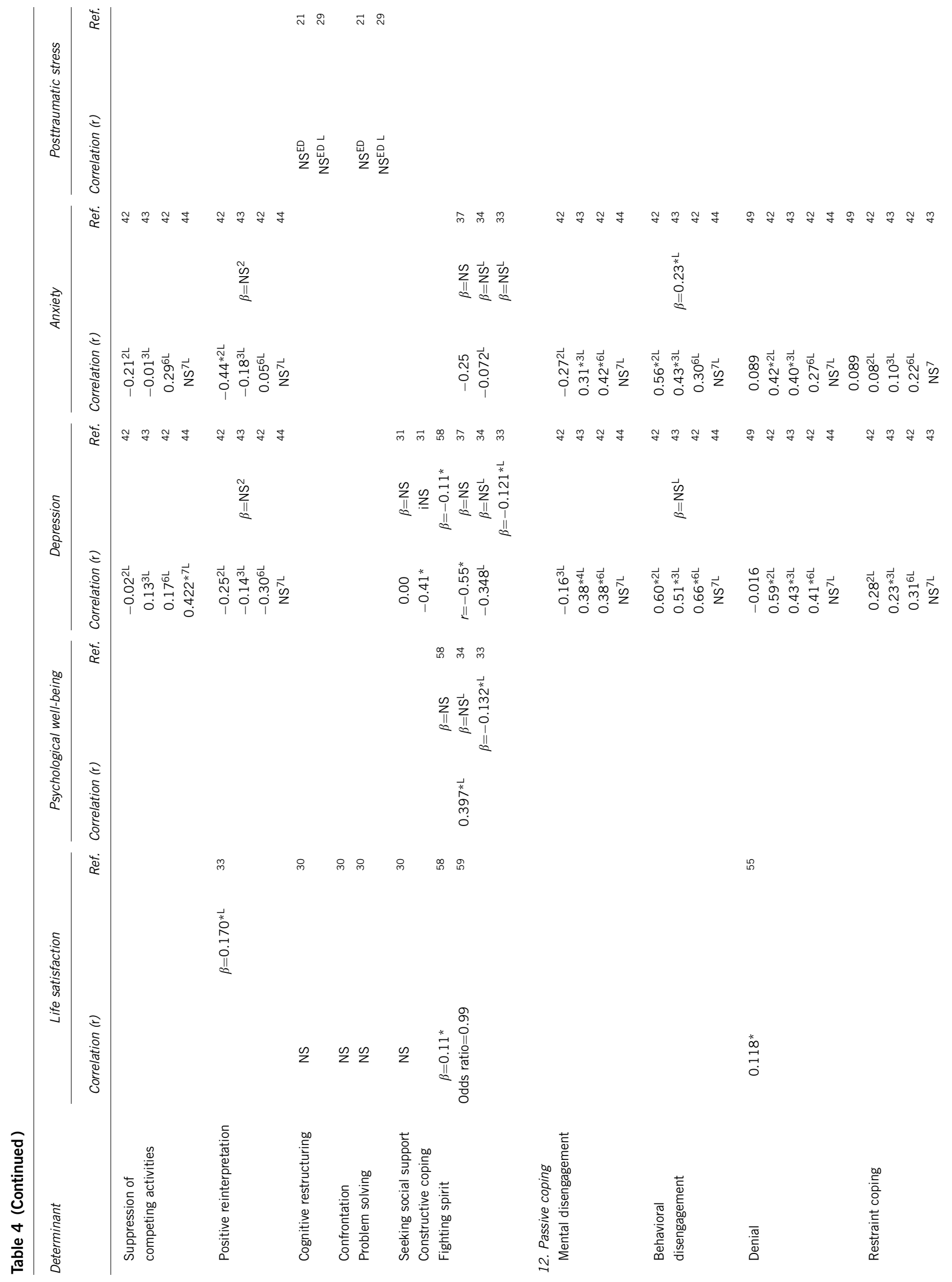




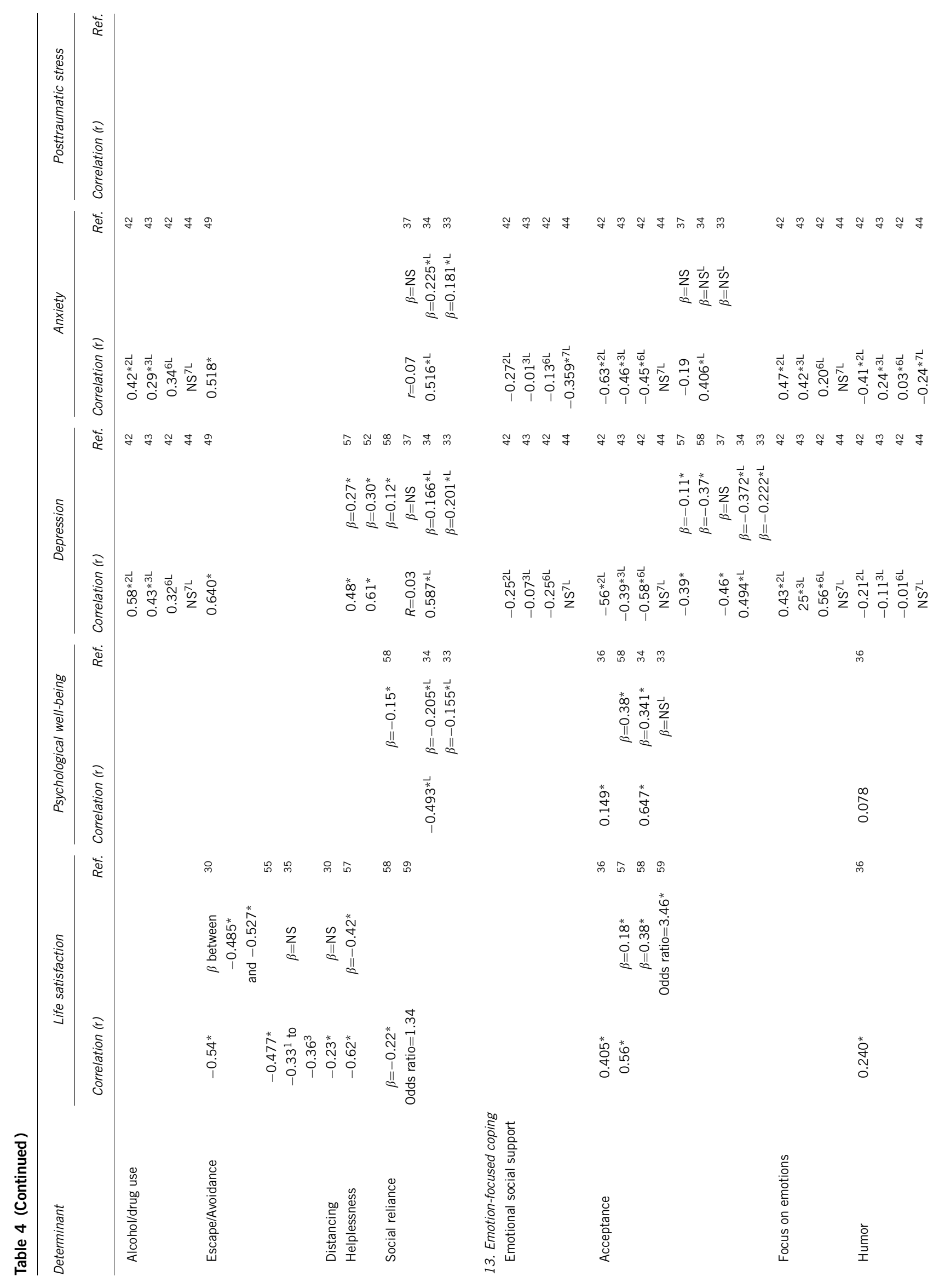




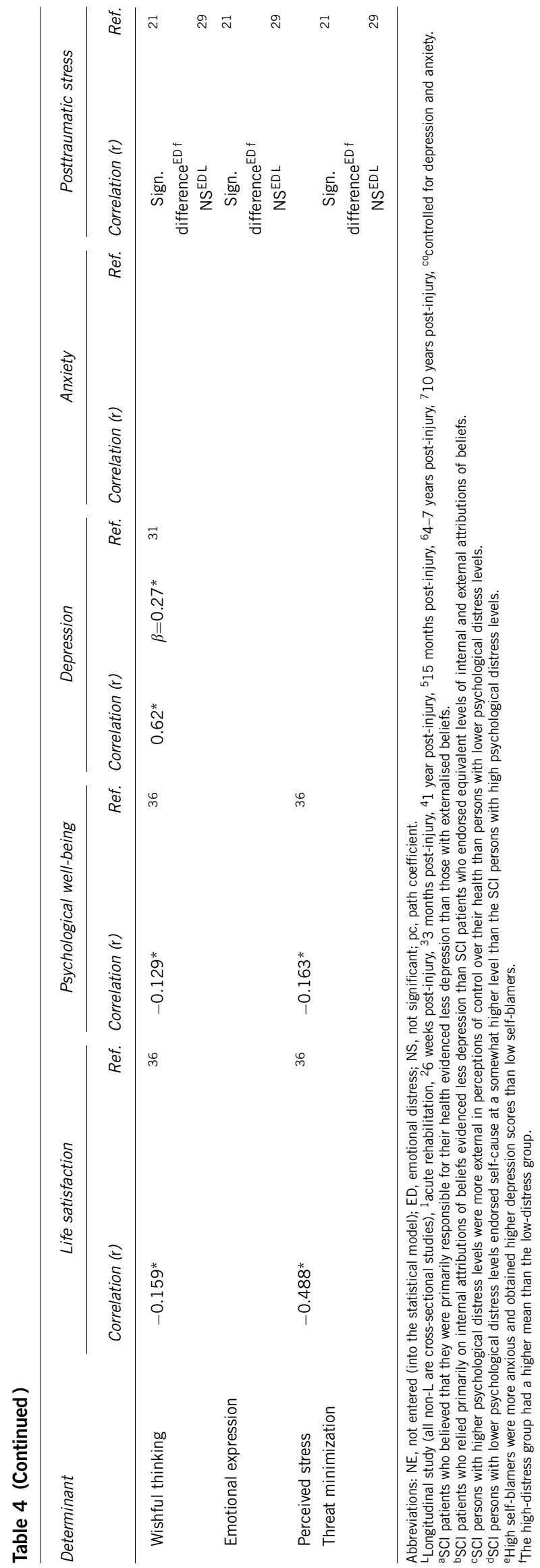

coherence, positive factors such as hope and purpose in life, feelings of self-worth, such as self-efficacy and self-esteem, positive and negative affect, and posttraumatic cognitions. A higher score on each of these determinants is related to greater QOL, except for negative affect and negative posttraumatic cognitions for which the inverse is true.

\section{Inconsistent determinants}

The psychological factors inconsistently associated with QOL outcomes include LOC components (as opposed to the total LOC score), attribution of blame, spirituality, personality measures, appraisals, emotion-focused coping styles and passive coping styles. All studies with respect to the LOC subcomponents were cross-sectional studies. Of the attribution of blame variables, self-blame and perceived avoidability are most frequently, but weakly, associated with QOL. For spirituality, research has focused more on religious than on existential aspects, yet existential spirituality was strongly associated with QOL in one study. ${ }^{40}$ Personality variables were only examined in two studies, of which only neuroticism and extraversion were associated with QOL. ${ }^{17,53}$ Appraisals were univariately associated with variable strength to QOL. ${ }^{33,34,37}$ Yet, only few of the multivariate associations were significant. ${ }^{33,34,37}$ This inconsistency may be because of coping variables being entered in the multivariate analysis along with appraisals, so that appraisals did not explain a substantial part of the variance in QOL beyond the variance that was explained by coping variables. This might also indicate a conceptual overlap between coping and appraisals, or between appraisals and QOL. Acceptance was a consistent determinant of QOL, yet the majority of emotion-focused coping styles were not associated with QOL. Of the passive coping styles, only helplessness was consistently related to QOL. ${ }^{52,57}$ Although behavioral disengagement, denial, avoidance and social reliance were moderately to strongly related to QOL in some studies, they were not consistently related to QOL across studies. ${ }^{30,33-35,37,42-44,49,55,58,59}$

\section{Determinants unrelated to QOL}

Surprisingly, none of the active problem-focused coping variables were consistently associated with QOL outcomes. An explanation for the lack of association between active problem-focused coping and QOL might be that in situations where goals are blocked, such as in the case with an SCI, actively adjusting life circumstances to one's personal preferences is not very effective. In such situations, adjusting personal preferences and goals to situational changes is more effective and more positively related to adjustment. ${ }^{61}$

\section{Comparison with previous reviews}

Some of the present findings coincide with conclusions from previous reviews. For instance, the notion that sense of coherence and purpose in life are associated with greater QOL, reiterates the findings of Chevalier et al. ${ }^{8}$ The importance of personal control to more favorable outcomes for persons with SCI was stressed by both North ${ }^{6}$ and Chevalier et al. ${ }^{8}$ The association between self-efficacy and QOL has also been reported. ${ }^{8}$ The present review strengthens the evidence for these psychological factors with the inclusion of a greater number of studies.

Unlike earlier reviews ${ }^{7,8}$ that underlined the importance of coping and appraisals in adjustment to SCI, the present review found inconsistent evidence for the role of both of these psychological factors in QOL. This is perhaps due to the fact that previous reviews only focused on significant associations, and did not report insignificant associations. The inconsistency may also have resulted from the inconsistent terminology with respect to coping and appraisals. The 
specific way in which a person with SCI 'copes' with his or her SCI, appears to be crucial for his or her QOL. Yet, consensus on the conceptualization and operationalization of 'coping' is lacking, as is illustrated by the large number of coping strategies that is described in the literature. The same conceptual confusion applies to appraisals. The way one appraises having an SCI appears crucial, yet it remains unclear how appraisals are defined and operationalized.

The present review identifies four additional psychological factors that are consistently related to QOL but have not been discussed in the earlier reviews: ${ }^{6-8}$ self-esteem, hope, affect (positive and negative) and posttraumatic cognitions. However, affect and posttraumatic cognitions may be a part of QOL rather than separate determinants. Although spirituality and personality were inconsistently related to QOL, existential spirituality, neuroticism and extraversion seem promising psychological factors of QOL as well and deserve further study.

\section{Clinical implications}

A group of psychological factors, including self-efficacy and selfesteem, were consistently related to better QOL. These variables may be seen as psychological resources that help people to regain their QOL after SCI. For example, people with high self-efficacy and high self-esteem might be more likely to take personal control over their future than people with low-self-efficacy, as they have a stronger belief in their ability to influence their situation for the better. Further research is necessary to distinguish the specific mechanisms behind the psychological factors that facilitate adjustment to SCI.

A variety of intervention studies are needed to identify optimal psychological support for persons with SCI. More insight into the factors that are consistently related to QOL could provide a guideline for such interventional studies. Self-management interventions aimed at training self-efficacy, philosophical counseling focused on stimulating purpose in life, and cognitive behavioral therapy aimed at changing cognitions and appraisals might all be effective interventions for improving the QOL of persons with SCI.

\section{Methodological limitations of the literature}

Several methodological limitations of the reviewed articles as a whole need to be addressed. First, the psychological terminology is often inconsistent, especially with respect to coping and appraisals. Acceptance, for instance, is used both as a coping variable and as an appraisal. ${ }^{33,34,36,37,42-44,57-59}$ Moreover, religiosity/spirituality have been employed both as a coping variable and as a determinant distinct from coping. ${ }^{40-43}$ There is thus little consensus in the literature of what exactly constitutes coping or appraisals.

A second limitation is the conceptual proximity between several dependent and independent variables used in the analysis. For instance, perceived stress is employed as an emotion-based coping variable in one study, and as a QOL outcome in others. Another example is the use of 'posttraumatic cognitions', which as a determinant entered in analysis, is suspiciously close to the outcome of posttraumatic stress. Moreover, affect is often part of QOL, instead of being a determinant of QOL. It is unclear to what degree these concepts measure the same underlying phenomenon. An overlap in measurement would in any case provide a plausible alternative explanation for any robust correlations found between these variables.

Other limitations concern the wide variety of questionnaires used, the overrepresentation of small studies and of studies with a crosssectional design.

The final limitation is that certain concepts that are widely studied at one point have subsequently fallen into disuse. The notion 'attribution of blame' is one such term, which has been examined in several studies in the 1980s and 1990s, after which it is rarely mentioned. Other concepts that have shown promise as determinants of QOL, yet lack follow-up studies, are personality and social comparison.

\section{Limitations of this systematic review}

First, the literature search was restricted to articles published in English, which may have excluded relevant studies in other languages. Second, the list for the methodological assessment of studies, although it was based on previous research, was largely constructed by the authors. Finally, no meta-analysis could be conducted because of the, with few exceptions, small number of studies per determinant, as well as the great variety of measurement instruments used by those studies.

\section{Further research}

Further research should (1) aim to incorporate larger study groups, preferably in longitudinal studies, (2) be critical of and precise in its terminology, and increase sensitivity to conceptual boundaries, avoiding conceptual overlap between determinants and outcomes, (3) seek to scrutinize and gain uniformity of questionnaires and (4) reexamine concepts, such as personality and social comparison, which have been cast aside prematurely in the literature.

\section{Conclusion and clinical recommendations}

There is considerable evidence for the role of psychological factors in the QOL of persons with SCI. Perceived control, a sense of coherence, self-worth, hope and purpose in life, are most consistently associated with QOL after SCI. Interestingly, two prevalent concepts in psychological literature, coping and appraisals, showed much less consistent results warranting further study. Longitudinal studies with sufficient sample size, more clearly specified and operationalized constructs, and uniformity in the use of questionnaires are needed. Professionals may optimize their care for a person with SCI by carefully monitoring the person's affective state, and by fostering the idea that he or she is a valuable person in control of his or her own life; a life that is essentially comprehensible, manageable and meaningful.

\section{CONFLICT OF INTEREST}

The authors declare no conflict of interest.

1 Glass C. Treatment and rehabilitation following spinal cord injury. Pers Injury Law Med Rev 1993; 38: 51-70.

2 Hammell KW. Exploring quality of life following high spinal cord injury: a review and critique. Spinal Cord 2004; 42: 494-502.

3 Post M, Noreau L. Quality of life after spinal cord injury. J Neurol Phys Ther 2005; 29 : 139-146.

4 Wade DT. Describing rehabilitation interventions. Clin Rehabil 2005; 19: 811-818.

5 Dijkers PJ. Quality of life in individuals with spinal cord injury: a review of conceptualization, measurement, and research findings. J Rehabil Res Dev 2005; 42: 87-110.

6 North NT. The psychological effects of spinal cord injury: a review. Spinal Cord 1999; 37: 671-679.

7 Galvin LR, Godfrey HP. The impact of coping on emotional adjustment to spinal cord injury (SCI): a review of the literature and application of a stress appraisal and coping formulation. Spinal Cord 2001; 39: 615-627.

8 Chevalier Z, Kennedy P, Sherlock O. Spinal cord injury, coping and psychological adjustment: a literature review. Spinal Cord 2009; 47: 778-782.

9 Ogden J. Health Psychology.. Open University Press: Berkshire, 2004.

10 Kwakkel G, Wagenaar R, Kollen B, Lankhorst G. Predicting disability in stroke-a critical review of the literature. Age Ageing 1996; 25: 479-489.

11 Downs S, Black N. The feasibility of creating a checklist for the assessment of the methodological quality both of randomised and non-randomised studies of health care interventions. J Epidemiol Community Health 1998; 52: 377-384.

12 Cohen J. Statistical Power Analysis For The Behavioural Sciences, 2nd edn. Lawrence Erlbaum Associates, Hillsdale, NJ, UK, 1988 
13 Boschen K, Tonack M, Gargaro J. Long-term adjustment and community reintegration following spinal cord injury. Int J Rehabil Res 2003; 26: 157-164.

14 Chase B, Cornille T, English R. Life satisfaction among persons with spinal cord injuries. J Rehabil 2000; 66: 14-20.

15 Schulz R, Decker S. Long-term adjustment to physical disability: the role of social support, perceived control, and self-blame. J Pers Soc Psychol 1985; 48: 1162-1172.

16 Krause J, Stanwyck C, Maides J. Locus of control and life adjustment: relationship among people with spinal cord injury. Rehabil Couns Bull 1998; 41: 162-173.

17 Thompson N, Coker J, Krause J, Henry E. Purpose of life as a mediator of adjustment after spinal cord injury. Rehabil Psychol 2003; 48: 100-108.

18 Frank R, Elliott T. Spinal cord injury and health locus of control beliefs. Paraplegia 1989; 35: 250-256.

19 Frank R, Umlauf R, Wonderlich S, Askanazi G, Buckelew S, Elliott T. Differences in coping styles among persons with spinal cord injury: a cluster-analytic approach. J Consult Clin Psych 1987; 55: 727-731.

20 Chung M, Preveza E, Papandreou K, Prevezas N. The relationship between posttraumatic stress disorder following spinal cord injury and locus of control. J Affect Disord 2006; 93: 229-232.

21 Buckelew S, Baumstark K, Frank R, Hewett J. Adjustment following spinal cord injury. Rehabil Psychol 1990; 35: 101-109.

22 MacLeod L, MacLeod G. Control cognitions and psychological disturbance in people with contrasting physically disabling conditions. Disabil Rehabil 1998; 20: $448-456$.

23 Waldron B, Benson C, O'Connell A, Byrne P, Dooley B, Burke T. Health locus of control and attributions of cause and blame in adjustment to spinal cord injury. Spinal Cord 2010; 48: 598-602

24 Agar E, Kennedy P, King N. The role of negative cognitive appraisals in PTSD symptoms following spinal cord injuries. Behav Cogn Psychother 2006; 34: 437-452.

25 Hatcher M, Whitaker C, Karl A. What predicts post-traumatic stress following spinal cord injury? Br J Health Psychol 2009; 14: 541-561.

26 Reidy K, Caplan B. Causal factors in spinal cord injury: patients' evolving perceptions and association with depression. Arch Phys Med Rehabil 1994; 75: 837-842.

27 Nielson W, MacDonald M. Attributions of blame and coping following spinal cord injury: is self-blame adaptive? J Soc Clin Psychol 1988; 7: 163-175.

28 Brown K, Bell M, Maynard C, Richardson W, Wagner G. Attribution of responsibility for injury and long-term outcome of patients with paralytic spinal cord trauma. Spinal Cord 1999; 37: 653-657.

29 Hanson S, Buckelew S, Hewett J, O'Neal G. The relationship between coping and adjustment after spinal cord injury: a 5-year follow-up study. Rehabil Psychol 1993; 38: 41-52.

30 Hansen N, Forchheimer M, Tate D, Luera G. Relationships among community reintegration, coping strategies, and life satisfaction in a sample of persons with spinal cord injury. Top Spinal Cord Inj Rehabil 1998; 4: 56-72.

31 Buunk A, Zurriaga R, González P. Social comparison, coping and depression in people with spinal cord injury. Psychol Health 2006; 21: 791-807.

32 O'Carroll R, Ayling R, O'Reilly S, North N. Alexithymia and sense of coherence in patients with total spinal cord transection. Psychosom Med 2003; 65: 151-155.

33 Kennedy P, Lude P, Elfström M, Smithson E. Cognitive appraisals, coping and quality of life outcomes: a multi-centre study of spinal cord injury rehabilitation. Spinal Cord 2010; 48: 762-769.

34 Kennedy P, Lude P, Elfström M, Smithson E. Sense of coherence and psychological outcomes in people with spinal cord injury: appraisals and behavioural responses. $\mathrm{Br} J$ Health Psychol 2010; 15: 611-621.

35 Kortte K, Gilbert M, Gorman P, Wegener S. Positive psychological variables in the prediction of life satisfaction after spinal cord injury. Rehabil Psychol 2010; 55 40-47.

36 Smedema S, Catalano D, Ebener D. The relationship of coping, self-worth, and subjective well-being: a structural equation model. Rehabil Couns Bull 2010; 53: $131-142$.

37 Kennedy P, Evans M, Sandhu N. Psychological adjustment to spinal cord injury: the contribution of coping, hope and cognitive appraisals. Psychol Health Med 2009; 14 17-33.
38 Mortenson W, Noreau L, Miller W. The relationship between and predictors of quality of life after spinal cord injury at 3 and 15 months after discharge. Spinal Cord 2009, 1-7.

39 deRoon-Cassini T, de St Aubin E, Valvano A, Hastings J, Horn P. Psychological wellbeing after spinal cord injury: perception of loss and meaning making. Rehabil Psychol 2009; 54: 306-314.

40 Matheis E, Tulsky D, Matheis R. The relation between spirituality and quality of life among individuals with spinal cord injury. Rehabil Psychol 2006; 51: 265-271.

41 Forcheimer M, Tate D. The relationship of spirituality and depression to health among people with spinal cord injury. Top Spinal Cord Inj Rehabil 2007; 12: 23-34.

42 Kennedy P, Lowe R, Grey, N, Short E. Traumatic spinal cord injury and psychological impact: a cross-sectional analysis of coping strategies. Br J Clin Psychol 1995; 34: 627-639.

43 Kennedy P, Marsh N, Lowe R, Grey N, Short E, Rogers B. A longitudinal analysis of psychological impact and coping strategies following spinal cord injury. $\mathrm{Br} \mathrm{J}$ Health Psychol 2000; 5: 157-172.

44 Pollard C, Kennedy P. A longitudinal analysis of emotional impact, coping strategies and post-traumatic psychological growth following spinal cord injury: a 10-year review. Br J Health Psychol 2007; 12: 347-362.

45 Tzonichaki I, Kleftaras G. Paraplegia from spinal cord injury: self-esteem, loneliness, and life satisfaction. OTJR Occup Participation Health 2002; 22: 96-105.

46 Coyle C, Lesnik-Emas S, Kinney W. Predicting life satisfaction among adults with spinal cord injuries. Rehabil Psychol 1994; 39: 95-112.

47 Hampton N. Disability status, perceived health, social support, self-efficacy, and quality of life among people with spinal cord injury in the People's Republic of China. Int J Rehabil Res 2001; 43: 69-71.

48 Hampton N. Subjective well-being among people with spinal cord injuries: the role of self-efficacy, perceived social support, and perceived health. Rehabil Couns Bull 2004; 48: 31-37.

49 Hampton N. Self-efficacy and quality of life in people with spinal cord injuries in China. Rehabil Couns Bull 2000; 43: 66-74.

50 Middleton J, Tran Y, Craig A. Relationship between quality of life and self-efficacy in persons with spinal cord injury. Arch Phys Med Rehabil 2007; 88: 1643-1648.

51 Elliott T, Godshall F, Herrick S, Witty T, Spruell M. Problem-solving appraisal and psychological adjustment following spinal cord injury. Cognit Ther Res 1991; 15: 387-398.

52 Shnek Z, Foley F, LaRocca N, Gordon W, DeLuca J, Schwartzman H et al. Helplessness, self-efficacy, cognitive distortions, and depression in multiple sclerosis and spinal cord injury. Ann Behav Med 1997; 19: 187-294.

53 Krause J, Rohe D. Personality and life adjustment after spinal cord injury: an exploratory study. Rehabil Psychol 1998; 43: 118-130.

54 Krause J, Dawis R. Prediction of life satisfaction after spinal cord injury: a four-year longitudinal approach. Rehabil Psychol 1992; 37: 49-60.

55 Martz E, Livneh H, Priebe M, Wuermser L, Ottomanelli L. Predictors of psychosocial adaptation among people with spinal cord injury or disorder. Arch Phys Med Rehabil 2005; 86: 1182-1192

56 Kennedy P, Smithson E, McClelland M, Short D, Royle J, Wilson C. Life satisfaction, appraisals and functional outcomes in spinal cord-injured people living in the community. Spinal Cord 2010; 48: 144-148.

57 Wollaars M, Post M, van Asbeck F, Brand N. Spinal cord injury pain: the influence of psychologic factors and impact on quality of life. Clin J Pain 2007; 23: 383-391.

58 Elfström M, Ryden A, Kreuter M, Taft C, Sullivan M. Relations between coping strategies and health-related quality of life in patients with spinal cord lesion. $J$ Rehabil Med 2005; 37: 9-16.

59 Migliorini $\mathrm{C}$, Tonge B. Reflecting on subjective well-being and spinal cord injury. J Rehabil Med 2009; 41: 445-450.

60 Moore A, Bombardier C, Brown P, Patterson D. Coping and emotional attributions following spinal cord injury. Int J Rehabil Res 1994; 17: 39-48.

61 Brandtstädter J, Renner G. Tenacious goal pursuit and flexible goal adjustment: explication and age-related analysis of assimilative and accommodative strategies of coping. Psychol Aging 1990; 5: 58-67.

Supplementary Information accompanies the paper on the Spinal Cord website (http://www.nature.com/sc) 